\title{
Moralitas Fanatisme Bonek Pelajar Di Surabaya (Studi Kasus Penanaman Moral Melalui Pendidikan Karakter di SMA YPP Nurul
Huda Surabaya)
}

\author{
Robert Tajuddin \\ SMAK Santa Agnes Surabaya \\ robert.tajuddin@yahoo.co.id
}

\begin{abstract}
Penelitian ini bertujuan untuk menjelaskan tentang moralitas fanatisme Bonek Pejalar di Surabaya dengan implementasi moralitas sebelum dan saat berada di dalam stadion mendukung Persebaya. Penelitian ini merupakan penelitian studi kasus dengan pendekatan kualitatif tentang penanaman moral melalui pendidikan karakter. Merujuk pada pendapat Thomas Lickona bahwa individu dapat disebut bermoral jika telah memiliki pengetahuan moral, perasaan bermoral, dan tindakan bermoral. Metode yang digunakan adalah deskriptif analitis dengan melakukan observasi, wawancara, dan dokumentasi. Data pendukung didapat dari jurnal, buku, dan internet yang berhubungan dengan penanaman moral dan moralitas fanatisme Bonek Pelajar. Pada tahap observasi implementasi moralitas fanatisme, peneliti menjadi "silent observer" agar perilaku alamiah subjek penelitian nampak jelas. Hasil penelitian berupa Bonek Pelajar setelah mempunyai bekal pengetahuan tentang perlunya moralitas, semua Bonek Pelajar selalu menjalankan ketertiban dengan baik. Namun beberapa dari Bonek Pelajar sesekali menyanyikan yel-yel rasis, dan satu dari enam subjek melakukan tindakan anarkis, maka perlu pendalaman moral lebih lanjut.
\end{abstract}

Keywords—Bonek Pelajar, Moralitas, Fanatisme

\section{PENDAHULUAN}

Bonek merupakan fenomena sosial masyarakat Indonesia. Dengan ciri khas anarkis, brutal, dan nekat yang selalu menghiasi sepak bola Indonesia. Awal mula massa Bonek mayoritas adalah golongan kaum menengah kebawah masyarakat Surabaya yang hanya bermodalkan nekat ketika harus mendukung Persebaya memang telah menjadi bagian tak terpisahkan dari persepakbolaan Indonesia, sehingga fenomena sosial berupa Bonek memerlukan penanganan, bertahap dan tepat sasaran untuk memberikan solusi bagi perkembangan persepakbolaan nasional. Penanganan untuk menurunkan intensitas anarkisme Bonek dilakukan secara kultural, yakni melalui pendekatan Bonek sendiri, seperti merubah simbol "wani" (berani dalam anarkis), menjadi "wani tertib" (berani melakukan ketertiban).

Disaat era keterpurukan Persebaya tahun 2010, komunitas Bonek Mania semakin mampu bertransformasi menjadi kelompok supporter sepak bola yang semakin menghilangkan ciri khas arogansi dan tindak anarkis (http://emosijiwaku.com), sehi-ngga menjadi kelompok supporter yang lebih dewasa dan mematuhi aturan hukum, dan "wani tertib" menjadi simbol baru bagi Bonek.

Perkembangan fanatisme Bonek yang menuju ke arah yang lebih baik merupakan sebuah fenomena perubahan sosial bagi para Bonek di semua kalangan, termasuk Bonek Pelajar di usia menengah atas (SMA). Bonek pelajar usia menengah atas ini sering disebut dengan Bonek Remaja. Bonek Remaja kerap kali dicap sebagai supporter yang susah untuk dikendalikan, mengingat gerak-gerik supporter tersebut sangat gesit dan licin, mengingat usia Bonek Remaja masih dalam usia labil. Bonek Pelajar berusia remaja ini merupakan anggota kelompok Bonek yang mampu merubah simbol "wani" ke arah yang lebih baik.

Fanatisme Bonek di usia labil ini menjadi sebuah studi kasus terkait penanaman moral melalui pendidikan karakter agar terbentuk fanatisme bermoral di kalangan Bonek Pelajar. Penelitian terdahulu terkait supporter pendukung mengungkap tentang fanatisme dan kekerasan antar supporter. Adapun moralitas dalam penelitian terdahulu dapat dikembangkan melalui lingkungan sekitar individu. Penanaman sebuah nilai moral terhadap Bonek usia menengah atas di Surabaya menjadi sebuah kajian penelitian kualitatif, sehingga penelitian ini memiliki fokus untuk memperoleh informasi mengenai bagaimana bentuk penanaman moral terhadap bonek pelajar dan bagaimana implementasi karakter bermoral bonek pelajar melalui kegiatan sinau bareng.

\section{METODE PENELITIAN}

Penelitian ini merupakan studi kasus menggunakan metode deskriptif analitis dengan pendekatan kualitatif. John W. Creswell dalam bukunya Qualitative Inquiry and Research Design: Choosing Among Five Tradition bahwa studi kasus sebuah eksplorasi dari suatu sis-tem yang terikat atau suatu kasus/beragam kasus yang dari waktu ke waktu melalui pengumpulan data yang mendalam serta melibatkan berbagai sumber informasi yang kaya dalam suatu konteks. Sistem terikat ini diikat oleh waktu dan tempat sedangkan 
kasus dapat dikaji dari suatu program, peristiwa, akti-vitas atau suatu individu dan organisasi.

Penelitian ini dilaksanakan selama satu tahun (20172018) dengan mengambil subjek penelitian yaitu bonek pelajar menengah atas sebanyak 6 siswa yakni Arianto, Abdu, Alvin, Muafi, Haris, Deva, dan guru sejarah sekaligus wakil kepala sekolah bagian kesiswaan dari para Bonek pelajar, yakni Moh. Amirul Mukminin, Abdul Mujib (guru ekonomi), dan Dian Yulia Rahmawati (Guru Sosiologi) yang akan menjadi pemateri dalam kegiatan sinau bareng. Tempat penelitian yaitu Kota Surabaya, khususnya SMA YPP Nurul Huda Surabaya.

Teknik pengumpulan data menggunakan metode observasi, wawancara dan dokumentasi. Kemudian, data yang dikumpulkan dianalisis dengan menggunakan teknik analisis data Miles dan Habbermas yaitu melalui tahapan pengumpulan data, reduksi data, display data, penarikan kesimpulan dan verifikasi.

\section{HASIL DAN PEMBAHASAN}

\section{A. Deskripsi SMA YPP Nurul Huda Surabaya}

Peneliti melakukan observasi tentang deskripsi SMA YPP Nurul Huda Surabaya yang bertempat di alamat Jalan Sencaki Nomor 64 Kecamatan Simokerto Kota Surabaya dengan kode pos 60144. SMA Nurul Huda Surabaya berada di bawah naungan Yayasan Pondok Pesantren Nurul Huda yang menganut Ajaran Ahlus-Sunnah Wal Jama'ah dalam bingkai Nahdlatul Ulama'. Ajaran Ahlus-Sunnah Wal Jama'ah dalam ajaran Islam berarti berpedoman terhadap Nabi Muhammad SAW sebagai tokoh Nabi (utusan Allah SWT dalam menyebarkan Islam). Berdasarkan hal tersebut, SMA YPP Nurul Huda sangat menjunjung tinggi moralitas dalam kehidupan siswa baik di dalam dan di luar lingkungan sekolah.

\section{B. Pembahasan}

\section{Penanaman Moral Bonek Pelajar pada Proses Perencanaan Materi Diskusi (Sinau Bareng)}

Proses Perencanaan Materi dilakukan dengan menyiapkan rancangan materi yang akan disampaikan dalam kegiatan Sinau Bareng History Community SMA YPP Nurul Huda Surabaya dengan tema "Mengenal Sosok Bung Tomo" dan "Moralitas dalam Kehiduan Sosial". Dalam diskusi tersebut akan dilakukan sebuah internalisasi penanaman karakter dalam tema kultur dan karakter Arek serta perlunya fanatisme bermoral bagi Bonek Pelajar.

Berdasarkan hasil rancangan materi menunjukan bahwa ada bagian yang menuliskan moralitas karakter yang akan ditanamkan di dalam materi. Pada bagian moralitas karakter yang dikem-bangkan ditulis dibagian kolom karakter siswa yang diharapkan serta pada tujuan pembelajaran. Ber-dasarkan hasil wawancara dan dokumentasi diambil kesimpulan bahwa perencanaan penanaman moral karakter adalah dengan menyiapkan materi pemb-ahasan. Pada tahap perencanaan ini peneliti juga menyiapkan materi tentang moralitas fanatisme Bonek.

\section{Penanaman Moral pada Tahap Pelaksanaan Diskusi (Sinau Bareng)}

Pada tahap ini penanaman moral terhadap Bonek Pelajar dilakukan melalui diskusi dalam kegiatan Sinau Bareng History Community SMA YPP Nurul Huda Surabaya dengan tema "Mengenal Sosok Bung Tomo", dan "Moralitas dalam Kehiduan Sosial". Pada tahap ini, guru mata pelajaran sejarah yang memimpin diskusi menyampaikan materi tentang sosok Bung Tomo dilanjutkan pemaparan peneliti yang memaparkan refleksi karakter Bonek Mania yang lebih baik, seperti perlunya karakter solidaritas kemanusiaan, tidak rasis, dan tidak anarkis seharusnya diterapkan dalam perilaku mbonek, sehingga fanatisme Bonek Pelajar menjadi fanatisme yang bermoral."

Dari hasil wawancara kepada para Bonek Pelajar setelah pemaparan materi penulis mendapatkan informasi bahwa Bonek Pelajar SMA YPP Nurul Huda Surabaya mampu mengolah makna "wani" dalam bentuk positif, yakni menjadi Bonek yang bermoral. Pendukung klub sepak bola yang mempunyai moralitas tidak akan merugikan diri sendiri, orang tua, mencemarkan nama sekolah, dan merugikan Persebaya.

\section{Implementasi Moralitas Fanatisme Bonek Pelajar SMA YPP Nurul Huda Surabaya saat menonton Persebaya (Mbonek)}

Bonek di kalangan pelajar sebagai bagian dari supporter pendukung Persebaya merupakan supporter yang dekat dengan moralitas, sehingga Bonek Pelajar juga dapat melakukan hal yang bermoral. Hal tersebut dikarenakan Bonek Pelajar masih usia sekolah, dan sekolah merupakan tempat pendidikan karakter bermoral untuk para siswa termasuk Bonek Pelajar.

Implementasi moralitas fanatisme Bonek Pelajar dilakukan dengan cara observasi dan dokumentasi. Observasi pada tahap ini dilakukan saat Persebaya melakukan pertandingan persahabatan melawan Serawak FA (dari Malaysia) pada 18 Maret 2018 dan laga Persebaya melawan PSIS Semarang pada 22 Juli 2018. Pada tahap observasi tentang implementasi moralitas fanatisme ini, peneliti menjadi "silent observer" agar perilaku alamiah subjek penelitian nampak jelas, sehingga obyektivitas penelitian tetap terjaga. Adapun data dokumentasi digunakan sebagai lampiran visualisasi pendukung hasil observasi.

Hasilnya adalah Bonek Pelajar setelah mem-punyai bekal pengetahuan tentang perlunya mor-alitas, semua Bonek Pelajar menjalankan ketertiban dengan baik. Namun beberapa dari Bonek Pelajar sesekali menyanyikan yel-yel rasis, dan satu dari enam subjek melakukan tindakan anarkis, maka perlu pendalaman moral lebih lanjut.

\section{Faktor Penghambat Pengimplementasian Moralitas Fanatisme Bonek Pelajar}

Berdasarkan proses obeservasi, wawancara, dan dokumentasi diperoleh beberapa faktor pengh-ambat yang dihadapi peneliti dalam pengimple-mentasian moralitas fanatisme Bonek Pelajar adalah sebagai berikut: 
a. Keterbatasan media sebagai alat peraga (seperti LCD) saat pengimplementasian moralitas fanatisme Bonek Pelajar dalam sebuah acara diskusi (sinau bareng). Hal ini dikarenakan kegiatan sinau bareng dilaksanakan di areal terbuka.

b. Kendala konsentrasi siswa yang terkadang fokus dengan gadget masing-masing, sehingga proses penanaman moralitas juga mengalami kendala.

Berdasarkan faktor penghambat tersebut perlu penyelesaian berupa ketersediaan alat peraga, serta penanaman kembali moralitas karakter agar siswa memperhatikan diskusi berisi pengintegrasian moralitas dalam kegiatan sinau bareng.

\section{Solusi yang dilakukan dalam Pelaksanaan Penanaman Moralitas terhadap Bonek Pelajar}

Berdasarkan faktor penghambat yang menjadi kendala pelaksanaan penanaman moralitas terhadap Bonek Pelajar ditemukan solusi berupa:

a. Perlu penyelesaian berupa ketersediaan alat peraga oleh pihak sekolah, sehingga proses penanaman moral terhadap Bonek Pelajar dapat berjalan baik.

b. Penanaman kembali moralitas karakter agar siswa memperhatikan diskusi berisi pengintegrasian moralitas dalam kegiatan sinau bareng, sehingga pengetahuan moral dapat dipahami dan diimplementasikan dengan baik.

\section{Keterbatasan Penelitian}

Subjek pengamatan yang diamati dalam penelitian ini adalah guru dan siswa di sekolah. Sikap dan perilaku subjek penelitian ketika berada di luar sekolah tidak diamati. Maka informasi diperoleh sebatas pada data di sekolah, sehingga memun-gkinkan subjek berperilaku lain ketika berada di rumah dan lingkungannya, sehingga peneliti tidak dapat mengungkap proses dan hasil penelitian yang komprehensif.

\section{DISKUSI HASIL PENELITIAN}

\section{A. Ketidaktercapaian Tujuan}

Subjek pengamatan yang diamati dalam penelitian ini adalah guru dan siswa di sekolah. Sikap dan perilaku subjek penelitian ketika berada di luar sekolah tidak diamati secara langsung. Dengan demikian informasi yang diperoleh hanya sebatas pada informasi dan data yang ada di sekolah, sehingga sangat memungkinkan subjek berperilaku lain ketika berada luar sekolah, sehingga peneliti tidak dapat mengungkapkan proses dan hasil penelitian yang komprehensif.

\section{B. Fisibilitas Penerapan Hasil di Lapangan}

Teori Solidaritas Mekanik oleh Emile Durkheim yang mengatakan bahwa solidaritas mekanik terbangun berdasarkan kesamaan kese-nangan, dan tidak berdasarkan pembagian sistem ke-rja. Bonek Pelajar SMA YPP Nurul Huda Surabaya telah aktif dalam kegiatan terkait Bonek maupun Persebaya seperti mendukung Persebaya baik secara langsung maupun tidak langsung.

Implementasi moralitas fanatisme Bonek Pel-ajar dalam penelitian inin dilakukan dengan cara ob-servasi dan dokumentasi. Observasi pada tahap ini dilakukan saat
Persebaya melakukan pertandingan persahabatan melawan Serawak FA (dari Malaysia) pada 18 Maret 2018. Pada tahap observasi tentang implementasi moralitas fanatisme ini, peneliti menjadi "silent observer" dan perilaku alamiah subjek penelitian saat mendukung Persebaya secara langsung di stadion nampak jelas, sehingga obyektivitas penelitian tetap terjaga. Menurut penulis, hal tersebut menjadi sebuah keterlaksanaan (fisibilitas) penerapan tujuan penelitian di lapangan menjadi sempurna.

\section{Argumentasi Terhadap Hasil yang Diperoleh}

Hal yang menjadi keunikan dalam penelitian ini adalah penulis mengungkap moralitas fanatisme kelompok pendukung berusia remaja melalui penanaman moral yang diintegrasikan dengan budaya sekolah.

Jurnal berjudul Perkembangan Nilai, Moral Dan Sikap Remaja karya Zuldafrial berisi tentang perkembanagan intelektual dalam kehidupan seseorang anak remaja harus diimbangi dengan nilai, moral serta akhlak yang baik. Anak yang tidak memiliki hubungan harmonis dengan orang tuanya di masa kecil kemungkinan besar tidak akan mampu mengembangkan superego yang cukup kuat, sehingga mereka bisa menjadi orang yang sering melanggar norma sosial. Kemandirian serta kematangan moral selalu mengedepankan dalam setiap tingkah laku dalam setiap kehidupan. Kemampuan yang ada dalam hidup seseorang anak menjadikan diri bisa memiliki akhlak serta sikap secara baik kedepannya.

Merujuk pada Zuldafrial, kematangan moral sangat dibutuhkan dalam realita kehidupan. Per-samaan dengan penelitian moralitas fanatisme Bonek Pelajar adalah pengetahuan moral harus diiringi perasaan dan perilaku bermoral. Hal yang menjadi pembeda dengan penelitian moralitas fanatisme Bonek Pelajar adalah fanatisme supporter dapat diarahkan menjadi lebih bermoral dalam habbit budaya sekolah.

\section{KESIMPULAN}

Bonek di kalangan pelajar adalah bagian dari supporter pendukung Persebaya yang merupakan supporter yang dekat dengan moralitas karena mengenyam pendidikan di sekolah, sehingga Bonek Pelajar juga dapat melakukan hal bermoral. Hal tersebut dikarenakan Bonek Pelajar masih usia sekolah, dan sekolah merupakan tempat pendidikan karakter bermoral untuk para siswa termasuk Bonek Pelajar.

Data tentang implementasi moralitas fanatisme Bonek Pelajar dilakukan dengan cara observasi dan dokumentasi. Observasi pada tahap ini dilakukan saat Persebaya melakukan pertandingan persahabatan melawan Serawak FA (dari Malaysia) pada 18 Maret 2018 dan laga Persebaya melawan PSIS Semarang pada 22 Juli 2018. Pada tahap observasi tentang implementasi moralitas fanatisme ini, peneliti menjadi "silent observer" agar perilaku alamiah subjek penelitian nampak jelas, sehingga obyektivitas penelitian tetap terjaga.

Hasilnya adalah Bonek Pelajar setelah mem-punyai bekal pengetahuan tentang perlunya mo-ralitas, semua Bonek Pelajar selalu menjalankan ke-tertiban dengan baik. Namun beberapa dari Bonek Pelajar sesekali menyanyikan yel-yel rasis, dan satu dari enam subjek melakukan tindakan anarkis, maka perlu pendalaman moral lebih lanjut. Merujuk pada 
teori moralitas Thomas Lickona bahwa kematangan moral sangat dibutuhkan dalam realita kehidupan yakni pengetahuan moral harus diiringi perasaan dan perilaku bermoral.

Berdasarkan keunikan, dan keterbatasan penelitian yang telah dibahas sebelumnya, peneliti dapat memberikan beberapa saran sebagai berikut:

1. Penelitian tentang moralitas fanatisme Bonek Pelajar ini menggunakan cara penanaman moralitas melalui pengintegrasian dalam kegiatan diskusi (sinau ba-reng) yang dapat dikembangkan oleh guru dalam melaksanakan penelitian pengem-bangan.

2. Hasil penelitian ini memerlukan penelitian lebih lanjut seperti menggunakan lebih banyak subjek penelitian, serta meng-gunakan penelitian pengembangan dengan desain yang lain agar menjadi lebih sem-purna.

3. Dalam mengembangkan kurikulum ter-masuk program ko-kurikulum hendaknya sekolah memperhatikan fenomena-feno-mena karakter dalam kehidupan, seperti perilaku supporter sepak bola, geng motor, dan lain sebagainya..

Berdasarkan hasil penelitian ini, terdapat beberapa implikasi kepada pihak yang berkompeten dalam proses penanaman karakter bermoral kepada semua siswa di sekolah. Guru dan para pemangku jabatan di sekolah beserta staf sekolah sangat berperan dan menentukan dengan otoritas yang dimiliki dalam proses penanaman karakter bermoral kepada semua siswa di sekolah. Oleh karena itu guru dan para pemangku jabatan di sekolah beserta staf sekolah perlu memiliki pengetahuan yang luas sehingga proses penanaman karakter dilakukan secara arif dan penuh kebijaksanaan.

Meskipun demikian, perilaku siswa diluar sekolah dapat dipengaruhi oleh lingkungan sekitar siswa tersebut berada. Maka diperlukan sebuah kerjasama dan komunikasi yang baik antara guru dan para pemangku jabatan di sekolah beserta staf sekolah, orang tua, keluarga, serta masyarakat sehingga dapat berperan dalam pembentukan karakter bermoral dan pembentukan kepribadian yang baik bagi siswa sebagai peserta didik. Hal tersebut perlu dilakukan agar kesadaran tentang karakter bermoral tumbuh dalam diri para siswa sebagai peserta didik sehingga menjadi insan yang bermartabat, bermanfaat bagi sesama, dan berperan dalam memajukan kehidupan bangsa

\section{REFERENCES}

Jurnal

Abalasei, B. (2012). Types of audience attending sports events in romania, 46, 3482-3486. https://doi.org/10.1016/j.sbspro.2012.06.089

Andayani, B., \& Psikologi, B. (2004). Tinjauan pendekatan ekologi tentang perilaku pengasuhan orangtua, (1), 44-60.

Artikel dalam Patriot, 2001, Mubarok, 2008 Jurnal penelitian psikologi Universitas 17 Agustus Surabaya.Http://google.com

Eko Setiawan. (2013). Relevansi Tingkat Pendidikan Terhadap Moralitas Suporter Bonek Di Surabaya. Jurnal Universitas Negeri Surabaya, (2013), 1-10. https://jurnalmahasiswa.unesa.ac.id/index.php/jurnalkesehatan-olahraga/article/viewFile/2356/5512

Freitas, L. De, Silva, M., \& Albuquerque, D. (2014). Access of wheelchair users in sportive mega events : the case of Confederation Cup. Procedia - Social and Behavioral Sciences, 162(Panam), 148-157. https://doi.org/10.1016/j.sbspro.2014.12.195

Implementasi, M., \& Ekologi, T. (2015). Implementasi Teori Ekologi Bronfenbrenner Dalam Membangun Pendidikan Karakter Yang Berkualitas Mujahidah 1, IXX(2), 171-185.
Kurniaty, R. (2014). Local Elites and Public Space Sustainability : the local elite roles in the presence and usage of public space in Malang Raya , Indonesia. Procedia Environmental Sciences, 20, 506515.https://doi.org/10.1016/j.proenv.2014.03.063

Kuswono. (2016). Membangun Karakterkebangsaan Melalui Budaya Sekolah: Potret Penanaman Nilai Karakter Di Sekolah Menengah. Prosiding Seminar Nasional Pendidikan IPS Dengan Tema "Membangun Karakter Kebangsaan Melalui Pendidikan IPS" Pada 10 Desember 2016 yang Diselenggarakan oleh Program Studi Magister Pendidikan IPS Pascasarjana Universitas Lampung, 853-855.

Mahmoud, M. (2014). Polarized discourse in the news. Procedia - Social and Behavioral Sciences, 134, 70-91. https://doi.org/10.1016/j.sbspro.2014.04.225

Melrose, A., Hampton, P., \& Manu, P. (2011). Safety at Sports Stadia. Procedia Engineering, 14, 2205-2211. https://doi.org/10.1016/j.proeng.2011.07.277

Mencapai, G., Sarjana, G., Komunikasi, I., Studi, P., Komunikasi, I., Sebelas, U., \& Surakarta, M. (2015). Pola Komunikasi Suporter Sepakbola (Studi Deskriptif Kualitatif Pola Komunikasi Arsenal Indonesia Suporter Solo).

Prasetyo, E., Mahadian, A. B., Ip, S., Ikom, M., Nurhayati, I. K., \& Hum, M. (n.d.). Konsep Diri Supporter Fanatik Viking Persib Club ( Studi Fenomenologi Supporter Fanatik Viking Persib Club dengan Status Sosial Ekonomi Menengah ke Bawah ), 1-8.

Publikasi, N. (2006). MENJADI SUPORTER Disusun oleh Arif Tri Handoko Sonny Andrianto Fakultas Psikologi Dan Ilmu Sosial Budaya Universitas Islam Indonesia Yogyakarta.

Remaja, D. A. N. S., \& Nilai, K. K. (n.d.). Perkembangan nilai, moral dan sikap remaja, 29-48.

Lucky, N., Rr, A., \& Setyowati, N. (n.d.). Perilaku Kekerasan Dari Suporter Bonek Dalam Perspektif Subkultur Kekerasan, 1(1), 180-195.

Sabarina, Y., \& Desiana, F. (n.d.). Konstruksi Identitas Suporter Sepakbola Di Indonesia ( Studi kasus pada Kelompok Suporter The Jakmania ), 4(April 2011), 60-78.

Santos, N., Mendes, A., \& Straub, R. (2014). ARTIGO ORIGINAL A invasão no estádio Couto Pereira em 2009: considerações sobre os discursos da imprensa escrita e da torcida organizada. Revista Brasileira de Ciências Do Esporte, 36(3), 617-625. https://doi.org/10.1590/2179325520143630002

Syadzwina, A. W. W., Akbar, M., \& Bahfiarti, T. (2014). Fenomenologi perilaku komunikasi suporter fanatik sepakbola dalam memberikan dukungan pada psm makassar, 3(1), 1-7.

Weisel, O., \& Böhm, R. (2015). Journal of Experimental Social Psychology "Ingroup love" and " outgroup hate" in intergroup con fl ict between natural groups. Journal of Experimental Social Psychology, 60, 110120. https://doi.org/10.1016/j.jesp.2015.04.008

Buku

Abdillah Autar. 2007. Budaya Arek Suroboyo. Tesis S-2, Surabaya: Pascasarjana Universitas Airlangga Surabaya (belum diterbitkan). 2007, "Perjalanan Panjang Budaya Arek". Surabaya: Jawa Pos, Selasa, 30 Oktober 2007 (Opini Metropolis) hal. 32.

Basofi Soedirman, dkk. 1997. Bonek Berani Karena Bersama. Surabaya: Hipotesa.

Basrowi dan Suwandi. 2008. Memahami Penelitian Kualitatif. Jakarta: Rineka Cipta.

Colombijn., Freek, Martine Barwegan, Purnawan Basundoro, Johny Alfian Khusyairi (ed.), 2005, Kota Lama, Kota Baru, Sejarah Kota-kota di Indonesia Sebelum dan Setelah Kemerdekaan (judul asli: Old City, New City, The History of the Indonesian City Before and After Independence, Yogyakarta: Ombak

Doyle Paul Johnson. 1994. Teori Sosiologi Klasik dan Modern. Jakarta: Gramedia Pustaka

Faber., G.H. Von, 1953, Sebuah kota lahir, Surabaya: N.V. Koninklijke Boekhandel en Drukkerij G. Kolff \& Co.

Giddens., Anthony, dan Jonathan Turner (eds.), 2008, Social Theory Today,Yogyakarta: Pustaka Pelajar

Hasanah. 2012. Pengembangan Profesi Guru.Bandung: Pustaka

Indriyanti, E. 2003. Hubungan Fanatisme dengan Agresifitas. Surabaya: Fakultas Psikologi Universitas 17 Agustus 1945 Surabaya.

Iskandar. 2009. Metodologi Penelitian Kualitatif. Jakarta: Gaung Persada Press

Lexy J. Moleong. 2005. Metode Penellitian Kualitatif. Bandung: PT Remaja Rosdakarya

Moestadji., H. Mohammad, 2003, Surabaya di Akhir Tahun 1945, Surabaya: CV. Agung Karya Perkasa.

Poerwandari, E. K. 2005. Pendekatan Kualitatif untuk Penelitian Perilaku Manusia. Depok: LPSP3 Fakultas Psikologi Universitas Indonesia 
Muljana., Slamet, 2006a, Menuju Puncak Kemegahan: Sejarah Kerajaan Majapahit,Yogyakarta: PT. LKiS Pelangi Aksara.

Nasution.2016. Kajian Pembelajaran IPS di Sekolah. Surabaya: Unesa University Press

Sindhunata. 2002. Catatan Sepakbola Sindhunata: Bola-bola Nasib. Jakarta: Penerbit Buku Kompas

Soekanto, S. 1990. Sosiologi, Suatu Pengantar. Jakarta: Rajawali Press

Sugiyarto, 1975, "Pengaruh Alam Terhadap Kehidupan Sepanjang Sungai Brantas". Dalam Wiwik Hidayat (ketua tim penyusun), Hari Jadi Kota Surabaya, Surabaya: Pemerintah Kotamadya Daerah Tingkat II Surabaya, hal. 43-64.

Suharsimi Arikunto. 2006. Prosedur Penelitian. Jakarta: Rineka Cipta

Sutopo. 2002. Metodologi Penelitian Kualitatif. Surakarta : UNS Press

Sutrisno., Mudji dan Hendar Putranto, (ed)., 2005, Teori-Teori Kebudayaan, Yogyakarta: Kanisius.

Umiarso \& Elbadiansyah. 2014. Interaksionisme Simbolik dari Era Klasik Hingga Modern. Jakarta : Rajawali Pers.

West, Ricard, Lynn H. Turner. 2008. Teori Komunikasi: Analisis dan Aplikasi. Jakarta: Salemba Humanika
Wirawan., I.B., 2013, Teori-teori Sosial dalam Tiga Paradigma (Fakta Sosial, Defenisi Sosial, dan Perilaku Sosial), Jakarta: Kencana.

Zoetmulder., P.J., bekerjasama dengan S.O Robson, 1995, Kamus Jawa Kuna Indonesia, 1 A-0 (penerjemah Daru Suprapto dan Sumarti Suprayitna, Jakarta: Gramedia Pustaka Utama.

Zuriah, Nurul. 2007. Pendidikan Moral dan Budi Pekerti Dalam Perspektif Perubahan. Jakarta: PT Bumi Aksara Internet

Autar Abdillah. 2015. Budaya Arek dan Malangan. Tinjauan Historis dan Diskursus Kebudayaan.

http://www.josstoday.com/read/2015/10/17/28021/BUDAYA_AREK_ DAN_MALANGAN__Tinjauan_Historis_dan_Diskursus_Kebudayaan , Diakses pada 19 Mei 2018. 2018.

SMA YPP Nurul Huda Surabaya. 2018 . Profil Sekolah SMA YPP Nurul Huda Surabaya.

https://yppnurulhuda.com/category/unit- pendidikan/ sma/ ., Diakses pada 12 Maret 2017.

Tim Penulis. 2016. https://emosijiwaku.com/2016/07/21/jakarta-2005sejarah-kelam- persebaya-dan-bonek/., Diakses pada 10 April 2017.

Tudji Martudji. 2017. https://nusantara.news/dari-tlatah-arek-bonekmendobrak-ketidakadilan-dan-arogansi/ ., Diakses pada 19 Mei 2018. 